\section{Anatomic predictors of intraocular pressure change after phacoemulsification: an AS-OCT study}

Norlina Ramli ${ }^{1}$, Li Yen Chan¹, Monisha Nongpiur ${ }^{2}$, Amir Samsudin¹, Mingguang $\mathrm{He}^{3}$, Mimiwati Zahari ${ }^{1}$

${ }^{1}$ University of Malaya Eye Research Centre, Department of Ophthalmology, Faculty of Medicine, University of Malaya, Kuala Lumpur, Malaysia; ${ }^{2}$ Singapore Eye Research Institute and Singapore National Eye Centre, Singapore, Singapore; ${ }^{3}$ Key Laboratory of Ophthalmology and Zhongshan Ophthalmic Center, Sun Yat-Sen University, Guangzhou, China

\section{Abstract}

Introduction: Phacoemulsification surgery is known to alter anterior segment structure parameters and also intraocular pressure (IOP). We set out in this study to investigate the relationship between the two parameters by using anterior segment optical coherence tomography (AS-OCT).

Purpose: To evaluate anterior segment and lens parameters associated with IOP lowering after phacoemulsification.

Study design: Prospective longitudinal single centre study.

Materials and methods: All consented study participants underwent uneventful phacoemulsification with foldable intraocular lens implantation. IOP measurement, gonioscopy, and AS-OCT measurements were performed pre- and postoperatively at one month. Customised software (Zhongshan Angle Assesment Programme, ZAAP) was used to measure various anterior chamber parameters. A-scan biometry

Correspondence: Associate Professor Norlina Ramli, University of Malaya Eye Research Centre, Department of Ophthalmology, Faculty of Medicine, University of Malaya, Kuala Lumpur, Malaysia.

E-mail:drnramli@gmail.com 
was used to measure axial length (AL), lens thickness (LT), and to calculate lens position (LP) and relative lens position (RLP).

Results: Eighty-six eyes from 86 patients were included in this study. The mean IOP reduced significantly after phacoemulsification (from $16.2 \pm 2.4 \mathrm{mmHg}$ to 14.1 $\pm 2.6 \mathrm{mmHg}$ at one week and $14.4 \pm 2.3 \mathrm{mmHg}$ at one month, $\mathrm{P}<0.001$ ). In the multivariate regression model, preoperative IOP and AL were the only significant parameters associated with percentage change in IOP $(p<0.001)$.

Conclusion: Change in IOP post-phacoemulsification is dependent on preoperative IOP and AL. Greater percentage change in IOP is seen in eyes with shorter axial length.

Keywords: angle-assessment programme, anterior segment optical coherence tomography (AS-OCT), axial length, intraocular pressure (IOP), phacoemulsification

\section{Kajian AS-OCT: peramal anatomi ke atas perubahan tekanan intraokular selepas fakoemulsifikasi}

\section{Abstrak}

Pengenalan: Pembedahan fakoemulsifikasi telah pun diketahui akan mengubah parameter struktur segmen anterior dan juga tekanan intraokular. Tujuan kami dalam kajian ini untuk menyiasat hubungan antara kedua-dua parameter dengan menggunakan segmen anterior OCT (ASOCT).

Tujuan: Untuk menilai parameter- parameter pada segmen anterior dan kanta yang dikaitkan dengan penurunan tekanan intraokular (IOP) selepas fakoemulsifikasi. Reka bentuk kajian: Prospektif, pusat kajian tunggal.

Bahan dan kaedah: Persetujuan diambil daripada semua peserta kajian yang menjalani fakoemulsifikasi tanpa komplikasi dengan implantasi kanta intraokular fleksibel. Pengukuran IOP, pengukuran gonioskopi dan AS-OCT dilakukan sebelum pembedahan dan pascapembedahan bulan pertama (1). Perisian yang disesuaikan (Zhongshan Angle Assessment Program, ZAAP) digunakan untuk mengukur pelbagai parameter ruang anterior. Biometri A-scan digunakan untuk mengukur panjang paksi (AL), ketebalan lensa (LT), dan untuk mengira kedudukan lensa (LP) dan kedudukan kanta relatif (RLP).

Keputusan: Lapan puluh enam mata daripada 86 pesakit dimasukkan ke dalam kajian ini. IOP min berkurang dengan ketara selepas fakoemulsifikasi (dari 16.2 $\pm 2.4 \mathrm{mmhg}$ kepada $14.1 \pm 2.6 \mathrm{mmhg}$ pada minggu 1 dan $14.4 \pm 2.3 \mathrm{mmhg}$ pada 
bulan $1, \mathrm{P}<0.001)$. Dalam model regresi multivariate, IOP pra-pembedahan dan panjang paksi adalah satu-satunya parameter penting yang dikaitkan dengan peratusan perubahan dalam IOP $(\mathrm{p}<0.001)$.

Kesimpulan: Perubahan dalam pascafakoemulsifikasi IOP bergantung kepada prapembedahan IOP dan panjang paksi. Peratusan perubahan yang lebih besar dalam IOP dilihat pada mata dengan panjang paksi yang lebih pendek.

Kata kunci: fakoemulsifikasi, segmen anterior OCT, tekanan intraokular, program penilaian sudut, panjang paksi

\section{Introduction}

The observation that intraocular pressure (IOP) often decreases after cataract surgery was first reported several decades ago., ${ }^{1,2}$ These studies reported a variation of $1.4 \mathrm{mmHg}$ to $13.5 \mathrm{mmHg}$ in mean IOP reduction. The exact mechanism by which cataract operation reduces IOP remains unknown. Proposed mechanisms include relief of subclinical or intermittent angle narrowing, widening of the trabecular meshwork spaces and Schlemm's canal, and the effects of ultrasonic vibrations that occur during phacoemulsification on the trabecular meshwork cytokine release. ${ }^{3-7}$

Anterior segment structures can be objectively assessed using advanced imaging, such as Scheimpflug photography, ultrasound biomicroscopy, and anterior segment optical coherence tomography (AS-OCT). Numerous studies have focused on changes in angle configuration 1 to 12 months after cataract surgery using ultrasound biomicroscopy. ${ }^{4,8,9}$ All studies report anterior chamber angle opening and anterior chamber deepening after cataract surgery. ${ }^{4,10-15}$ Furthermore, it was reported that postoperative lowering of IOP was proportional to the increase in anterior chamber angle opening after phacoemulsification in eyes with narrow angles and open angles. ${ }^{14,16,17}$ Huang et al. used AS-OCT to show that greater angle opening after cataract removal was significantly correlated with anterior chamber biometric factors, such as higher lens vault (LV), greater iris curvature (I-Curv), smaller trabecular-iris surface area (TISA), shallower anterior chamber depth (ACD), and narrower anterior chamber angle. ${ }^{14}$ They also found that preoperative LV was a significant factor in IOP reduction. However, the association of other lens parameters, such as lens thickness (LT), lens position (LP), and relative lens position (RLP), as predictors of angle widening after cataract surgery were not investigated in their paper.

The purpose of this study was to determine the effects of phacoemulsification with intraocular lens (IOL) on IOP and anterior segment biometric parameters and, in particular, the association of lens biometric factors with anterior chamber angle widening and IOP reduction after surgery. 


\section{Methods}

\section{Data collection}

This was a prospective, single centre study on patients undergoing phacoemulsification with IOL replacement at the University of Malaya Medical Centre (UMMC), Kuala Lumpur, Malaysia. This study adhered to the Declaration of Helsinki and Good Clinical Practice guidelines. Institutional review board approval was obtained from the Medical Ethics Committee of the University of Malaya Medical Centre prior to the start of the study. Written informed consent was obtained from all patients who agreed to participate in the study.

Inclusion criteria for patients included those scheduled to undergo routine phacoemulsification, at least 21 years of age, able to give informed consent, and possessing baseline IOP measurement of $21 \mathrm{mmHg}$ or less on three different occasions preoperatively. The exclusion criteria included:

1. previous penetrating ocular surgery or refractive surgery;

2. primary or secondary glaucoma, peripheral and posterior anterior synechiae, glaucomatous optic neuropathy, or the use of topical glaucoma therapy;

3. substantial corneal abnormality, for example, corneal oedema, dystrophy, abrasion, marginal degeneration, and pterygium causing poor AS-OCT imaging quality;

4. vertical cup-to-disc ratio greater than 0.5 , which may be consistent with glaucoma; and

5. complications related to the cataract surgery, for example, posterior capsule rupture and vitreous loss.

\section{Pre- and postoperative evaluation}

Preoperative evaluation included visual acuity testing, slit lamp examination, funduscopy, IOP measurement, gonioscopy, and biometry. Gonioscopy was performed using a Zeiss 4-mirror gonioscopy lens (Ocular Instruments, Bellavue, WA, USA) by a single glaucoma specialist (MZ) in a dark room setting. The Shaffer method of grading was used to grade all four quadrants. IOP was measured using Goldmann applanation tonometry by a single masked observer. Two readings were taken several minutes apart, and a separate observer read the measurement. If the two measurements differed by more than $2 \mathrm{mmHg}$, a third reading was taken and the average of three measurements was recorded. Patients were assessed within a narrow period of the day ( $9 \mathrm{am}-1 \mathrm{pm})$ to reduce the effect of diurnal IOP fluctuation. Biometry was performed after slit lamp examination using an optical biometry device (Lenstar LS900, Haag-Streit AG, Bern, Switzerland). Axial length (AL) and lens thickness (LT) values were obtained from this device.

Following surgery, patients were reviewed in the eye clinic of UMMC at one week and one month postoperatively. All patients were given a postoperative regime of 
tobramycin eye drops at two hourly intervals for the first week, which was tapered to four times daily for the following three weeks. At each visit, best-corrected visual acuity, slit lamp examination, IOP determination, and AS-OCT scan were performed by the same observer.

\section{AS-OCT findings}

Images of the anterior segment were collected by a single operator (LYC) two weeks before and one month after phacoemulsification cataract surgery using a commercially available AS-OCT device (Visante OCT; Carl Zeiss Meditec Inc., Dublin, California, USA). Standard resolution scans captured temporal and nasal quadrants in one image with the patient looking straight ahead. Only nasal and temporal quadrant images were included in this study, as assessment of the superior and inferior quadrants often requires manual manipulation of the eyelids, which may distort the angles. All the images were taken in the same dark conditions ( $0-1$ lux ambient light by digital light meter [Easy View model EA30; Extech Instruments, Inc., Waltham, MA, USA]) with the patient sitting upright. Several scans were acquired by the operator, and only images with no motion artefacts or image artefacts resulting from the eyelids were chosen for analysis.

Images were analysed using the Zhongsan Angle Assesment Programme (ZAAP, Guangzhou, China), which has been shown to have good reproducibility for iris and corneal measurements by a single observer. ${ }^{18,19}$ For each image, the only input by the observer was to determine the location of the two scleral spurs. The software then automatically calculates various parameters of the iris, cornea, and lens using automated identification of the anterior and posterior surfaces of the cornea, iris, and anterior surface of the lens. The images used for analysis were standard resolution images. Images were not used if scleral spurs were not located or a software delineation error occurred.

Anterior chamber parameters, such as anterior chamber depth (ACD), anterior chamber width (ACW), anterior chamber area (ACA), anterior chamber volume (ACV), angle opening distance (AOD) at 500 microns and 750 microns, and lens vault (LV) based on AS-OCT imaging, were compared preoperatively and one week and one month postoperatively.

Anterior vault (AV) was calculated as $A C D+L V$ and relative $L V(R L V)$ was calculated by dividing the LV by AV. The intra-observer reproducibility of the iris measurements was assessed using a random subset of 20 preoperative images. A single observer (LYC) analysed the images twice on occasions separated by an interval of at least one month.

\section{Surgical technique}

A consultant ophthalmologist (NR) performed all the cataract removals using conventional phacoemulsification. After a $2.75 \mathrm{~mm}$ clear corneal tunnel incision, a continuous curvilinear capsulorrhexis measuring approximately 5 to $6 \mathrm{~mm}$ in 
diameter was created using a cystotome and Utrata forceps. Hydrodissection/ hydrodelineation, phacoemulsification, cortical aspiration, insertion of a foldable acrylic IOL in the capsular bag and intracameral carbachol instillation at the end of surgery were then performed step by step. All the participating patients received a single-piece acrylic IOL in their eyes.

\section{Statistical analysis}

Statistical analysis was performed using the statistical package IBM SPSS Statistics for Windows (Version 21.0; IBM Corp., Armonk, NY, USA). Paired t-test was used to assess the one-month postoperative changes in the continuous variables. Univariate linear regression analyses adjusted for age and sex were performed for baseline parameters with percentage change in mean IOP (calculated as follows: difference in IOP at one month and preoperative IOP/preoperative IOP multiplied by 100 ) as the dependent variable. This was followed by a multivariate linear regression analysis using baseline parameters that showed significance at 0.20 levels in univariate analysis, excluding those that showed multicollinearity. Variance inflation factor and tolerance were calculated to test potential multicollinearity among the independent variables. The R2 was evaluated to examine the adequacy of the multiple linear regression models. Intra-observer agreement and inter-mode (standard and enhanced resolution images) agreement were performed to assess the repeatability of AS-OCT images. Probability values less than 0.05 were considered statistically significant.

\section{Results}

A total of 108 eyes from 108 patients had uneventful phacoemulsification and agreed to participate in the study during the specified time period. Among them, 22 patients were excluded from the study, as 18 had software delineation errors and 6 had poor visualisation of the scleral spurs on AS-OCT images. With the exclusions, 86 eyes $(79.63 \%)$ were eligible for the final analysis. Twelve eyes $(13.95 \%)$ had Schaffer grades of 2 or less in $\geq 2$ quadrants by gonioscopy, and 74 (86.05\%) eyes had Schaffer grades of 3 or 4 in $\geq 2$ quadrants. Table 1 provides the patient demographics and baseline clinical data.

Table 2 lists the pre- and posoperative measurements of IOP, AOD500, ACD, ACA, ACW, ACV, and central corneal thickness (CCT) by one-way analysis-of-variance (ANOVA) models and multiple-comparison tests. Significant increases in the angle and anterior segment parameters were observed at one month after phacoemulsification with IOL implantation. Significant changes were present in terms of IOP and angle parameters.

Table 3 shows the age and sex adjusted univariate regression model, indicating the association between percentage reduction in IOP after phacoemulsification and 
Table 1. Baseline demographics and ocular parameters of patients

\begin{tabular}{|l|l|l|}
\hline N = 86 & Mean \pm SD & Range \\
\hline Age (years) & $63.70 \pm 8.75$ & $30-78$ \\
\hline IOP (mmHg) & $16.24 \pm 2.46$ & $10-22$ \\
\hline AOD750 (mm) & $0.652 \pm 0.288$ & $0.15-1.71$ \\
\hline TISA750 (mm) & $0.368 \pm 0.18$ & $0.05-1.05$ \\
\hline IT750 (mm) & $0.461 \pm 0.07$ & $0.33-0.68$ \\
\hline Iarea (mm $\left.{ }^{2}\right)$ & $1.683 \pm 0.23$ & $1.26-2.72$ \\
\hline ICurv (mm) & $0.280 \pm 0.13$ & $0.04-0.69$ \\
\hline Ivolume (mm $\left.{ }^{3}\right)$ & $16.486 \pm 2.20$ & $11.98-22.45$ \\
\hline ACD (mm) & $2.892 \pm 0.39$ & $2.12-3.99$ \\
\hline ACW (mm) & $11.40 \pm 0.37$ & $10.44-12.19$ \\
\hline ACA (mm $\left.{ }^{2}\right)$ & $21.87 \pm 3.76$ & $15.59-33.63$ \\
\hline ACV (mm $\left.{ }^{3}\right)$ & $91.01 \pm 19.13$ & $58.92-148.58$ \\
\hline Pupil diameter (mm) & $3.63 \pm 0.85$ & $1.72-5.81$ \\
\hline AV (mm) & $3.049 \pm 0.19$ & $2.48-3.57$ \\
\hline RLV (mm) & $0.051 \pm 0.12$ & $-0.22-0.29$ \\
\hline AL (mm) & $23.860 \pm 1.26$ & $21.8-27.8$ \\
\hline LT (mm) & $4.437 \pm 0.70$ & $2.41-5.90$ \\
\hline LP (mm) & $5.044 \pm 0.34$ & $3.60-5.98$ \\
\hline RLP (mm) & $0.211 \pm 0.02$ & $0.164-0.260$ \\
\hline
\end{tabular}

Intraocular pressure: IOP; angle opening distance at 750 microns from scleral spur: AOD 750; trabecular-iris surface area: TISA; iris thickness: IT; iris area; Iarea; iris curvature: Icurv; iris volume Ivolume; anterior chamber depth: ACD; anterior chamber width: ACW; anterior chamber area: ACA; anterior chamber volume: ACV; lens vault: LV; anterior vault: $A V$, calculated as $A C D+L V$; relative lens vault: RLV, calculated by dividing the LV by AV; axial length: AL; lens thickness: LT; lens position: LP; relative lens position: RLP 
Table 2. Changes in mean anterior segment parameters following cataract extraction

\begin{tabular}{|l|l|l|l|l|}
\cline { 2 - 5 } \multicolumn{1}{l|}{} & Preop & $\begin{array}{l}\text { 1 month } \\
\text { postop }\end{array}$ & $\begin{array}{l}\text { Mean difference } \\
(95 \% \mathrm{CI})\end{array}$ & P-value \\
\hline IOP (mmHg) & $16.24 \pm 2.46$ & $14.47 \pm 2.39$ & $1.77(1.22,2.31)$ & $<0.001$ \\
\hline AOD750 & $0.64 \pm 0.29$ & $1.02 \pm 0.21$ & $-0.38(-0.46,-0.29)$ & $<0.001$ \\
\hline TISA750 & $0.36 \pm 0.18$ & $0.55 \pm 0.13$ & $-0.19(-0.24,-0.15)$ & $<0.001$ \\
\hline IT750 & $0.46 \pm 0.07$ & $0.44 \pm 0.08$ & $-0.19(-0.24,-0.14)$ & 0.19 \\
\hline Iarea & $1.65 \pm 0.24$ & $1.64 \pm 0.21$ & $0.01(-0.07,0.09)$ & 0.88 \\
\hline ICurv & $0.29 \pm 0.13$ & $0.18 \pm 0.08$ & $0.11(0.07,0.14)$ & $<0.001$ \\
\hline Ivolume & $16.54 \pm 2.26$ & $15.94 \pm 2.04$ & $0.59(-0.21,1.39)$ & 0.15 \\
\hline ACD (mm) & $2.89 \pm 0.3$ & $4.11 \pm 0.30$ & $-1.24(-1.35,-1.13)$ & $<0.001$ \\
\hline ACW (mm) & $11.40 \pm 0.37$ & $11.35 \pm 0.36$ & $0.04(-0.65,0.15)$ & 0.44 \\
\hline ACA (mm $\left.{ }^{2}\right)$ & $21.87 \pm 3.76$ & $28.77 \pm 2.64$ & $-7.17(-8.19,-6.17)$ & $<0.001$ \\
\hline ACV (mm $\left.{ }^{3}\right)$ & $91.01 \pm 19.13$ & $115.88 \pm 13.62$ & $-26.11(-31.32$, & $<0.001$ \\
\hline Pupil & $3.65 \pm 0.86$ & $3.45 \pm 0.72$ & $0.19(-0.04,0.43)$ & 0.11 \\
\hline
\end{tabular}

Analysis done with paired t-test. Intraocular pressure: IOP; angle opening distance at 750 microns from scleral spur: AOD750; trabecular-iris surface area: TISA; iris thickness: IT; iris area: Iarea; iris curvature: Icurv; iris volume: Ivolume; anterior chamber depth: ACD; anterior chamber width: ACW; anterior chamber area: ACA; anterior chamber volume: ACV 
Table 3. Linear regression analysis of the determinants for postoperative percentage IOP change

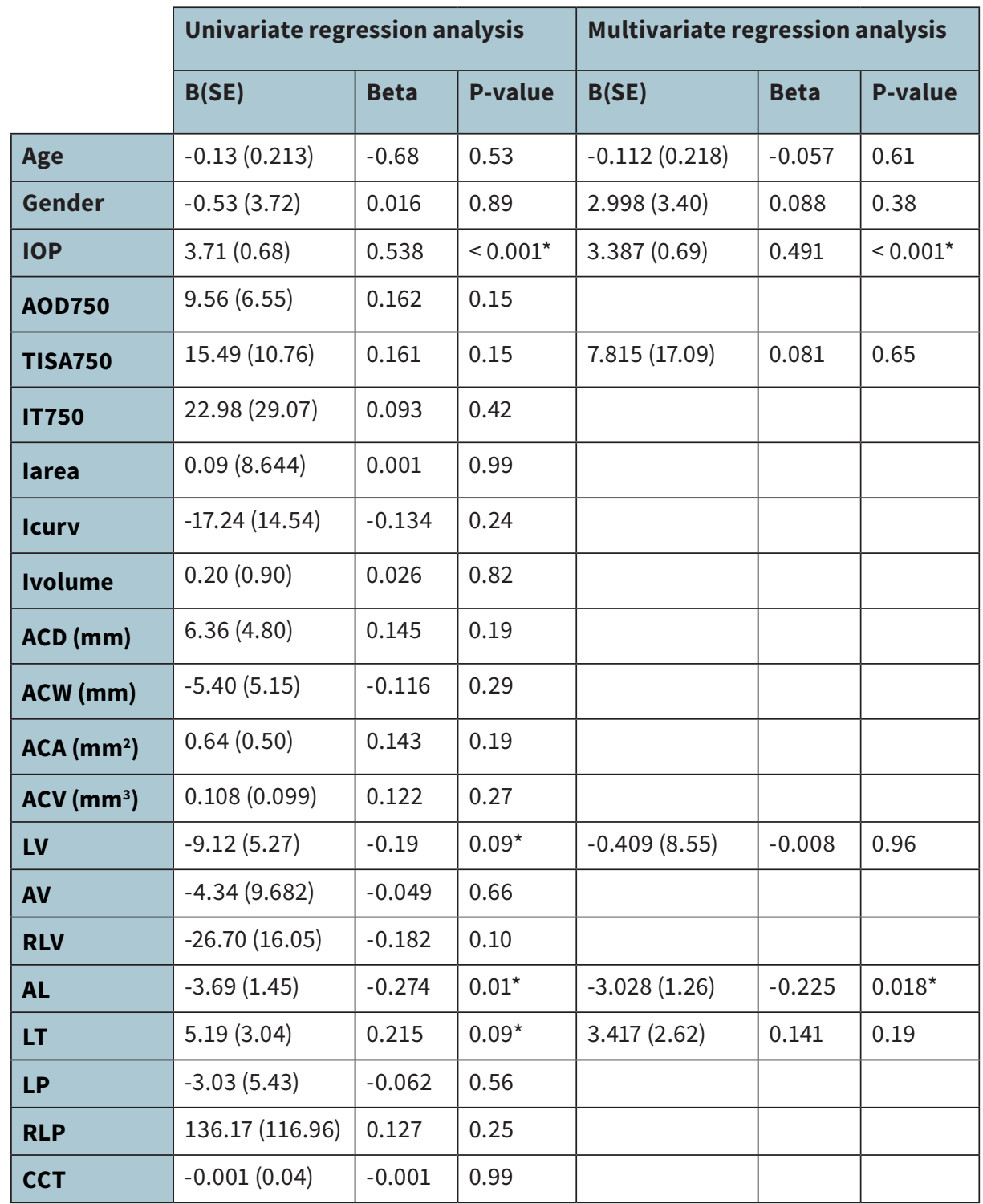

Intraocular pressure: IOP; angle opening distance at 750 microns from scleral spur: AOD750; trabecular-iris surface area: TISA; iris thickness: IT; iris area: Iarea; iris curvature: Icurv; iris volume Ivolume; anterior chamber depth: ACD; anterior chamber width: ACW; anterior chamber area: ACA; anterior chamber volume: ACV; lens vault: LV; anterior vault: $A V$, calculated as $A C D+L V$; relative lens vault: RLV, calculated by dividing the LV by AV; axial length: AL; lens thickness: LT; lens position: LP; relative lens position: RLP; central corneal thickness: CCT 
various preoperative ocular parameters. Preoperative parameters such as IOP, TISA $750, \mathrm{LV}, \mathrm{AL}$, and LT were considered significant at $\mathrm{p}<0.20$ value. Further multivariate regression analysis of these five parameters showed that only preoperative IOP and $\mathrm{AL}$ remained statistically significant.

\section{Discussion}

This study showed significant reduction of IOP at one week and one month after phacoemulsification, with mean IOP reduction of $1.77 \mathrm{mmHg}$ at one month postoperatively. The present findings were similar to previous studies conducted in non-glaucomatous patients, which showed a reduction in IOP between $1.26 \mathrm{mmHg}$ and $2.82 \mathrm{mmHg} .{ }^{13,14,20}$ This study suggests that after adjusting for age and sex, preoperative IOP and AL are independent predictors of reduction in IOP after surgery.

Prediction of IOP reduction post-phacoemulsification has been the subject of various studies. ${ }^{13,14,16,17}$ Some have come up with novel indexes, such as preoperative IOP to preoperative ACD ratio. ${ }^{16}$ Yet others have associated preoperative anatomic parameters measured by biometry, UBM, or AS-OCT with postoperative IOP reduction. ${ }^{12,14,21}$

We did not find any lens parameters (LV, LT, LP, RLP) that predicted the postoperative reduction in IOP. This differs from the findings of Huang et al., which showed LV to be significantly correlated with IOP reduction after cataract surgery. ${ }^{14}$ This disparity may be due to a difference in study patients. In the study by Huang et al., there was a higher percentage of angle closure eyes (39.73\%) compared to ours $(13.95 \%)$, which corresponds to their higher LV mean of $580 \mu \mathrm{m}$ when compared to $157 \mu \mathrm{m}$ in our study.

Yang et al. also found LT, ACA, and AOD500 to be significant factors in predicting IOP change after phacoemulsification. ${ }^{20}$ Two other studies showed that IOP reduction in angle closure was significantly greater than in open angle eyes..$^{4,13}$ Due to the limited number of angle closure patients in our cohort, we were unable to make any meaningful comparisons between this group and the open angle patients. We did however find that AL measurements were inversely proportional to percentage IOP change. This seems to support the findings that shorter eyes, which are more likely to be hypermetropic, show significant IOP change post-phacoemulsification. Yet another study found that, along with high iris cross-sectional area and convex hull of the iris, preoperative IOP was a good predictor of long-term IOP reduction post-phacoemulsification. ${ }^{21}$ Our study did not find these parameters significant.

We suspect that small differences in outcome are related to the differences in assessing the anterior chamber and lens parameters. Similar to our study, Huang et al. utilised the ZAAP software for image processing and subsequent calculations. ${ }^{13,14}$ Others have used customised software (ImageJ software; National Institutes of Health, Bethesda, Maryland, USA $)^{20}$ or have calculated parameters using simple 
measurement software available on the AS-OCT machine itself. ${ }^{11,21,22}$ Differences in measurement methods, whether by manual or by customised software on the AS-OCT may account for the discrepancy in study findings. This issue has also been seen in previous studies using UBM or gonioscopic assessment that were open to subjective errors in assessment and marking of anatomical landmarks. . $^{8,10,12,16}$

There were several limitations to our study. The number of participants having angle closure eyes was very small. As such, we were unable to assess if there were differences between angle closure and open angle eyes. Additionally, the follow-up of one month was relatively short in duration. As corneal biomechanical properties (including corneal rigidity) change in the early postoperative period, this may affect the IOP measurement. Corneal biomechanical parameters will reach preoperative values by three months after phacoemulsification. ${ }^{23}$ Therefore, a longer follow-up of at least three months would have been more accurate in evaluating the long-term association between IOP reduction and anterior chamber and lens parameters after phacoemulsification.

\section{Conclusion}

In conclusion, this study has shown that IOP reduction post-phacoemulsification is predicted by preoperative IOP and AL. Eyes with shorter AL demonstrate greater postoperative IOP reduction. Angle and lens parameters measured with AS-OCT did not predict percentage of IOP reduction in patients undergoing routine phacoemulsification surgery.

\section{References}

1. Handa J, Henry JC, Krupin T, Keates E. Extracapsular cataract extraction with posterior chamber lens implantation in patients with glaucoma. Arch Ophthalmol. 1987;105(6):765-769.

2. Suzuki R, Tanaka K, Sagara T, Fujiwara N. Reduction of intraocular pressure after phacoemulsification and aspiration with intraocular lens implantation. Ophthalmologica. 1994;208(5):254-258.

3. Poley BJ, Lindstrom RL, Samuelson TW. Long-term effects of phacoemulsification with intraocular lens implantation in normotensive and ocular hypertensive eyes. J Cataract Refract Surg. 2008;34(5):735-742.

4. Hayashi K, Hayashi H, Nakao F, Hayashi F. Changes in anterior chamber angle width and depth after intraocular lens implantation in eyes with glaucoma. Ophthalmology. 2000;107(4):698-703.

5. Meyer MA, Savitt ML, Kopitas E. The effect of phacoemulsification on aqueous outflow facility. Ophthalmology. 1997;104(8):1221-1227.

6. Wang N, Chintala SK, Fini ME, Schuman JS. Ultrasound activates the TM ELAM-1/IL-1/NF-kappaB response: a potential mechanism for intraocular pressure reduction after phacoemulsification. Invest Ophthalmol Vis Sci. 2003;44(5):1977-1981. 
7. Poley BJ, Lindstrom RL, Samuelson TW, Schulze R, Jr. Intraocular pressure reduction after phacoemulsification with intraocular lens implantation in glaucomatous and nonglaucomatous eyes: evaluation of a causal relationship between the natural lens and open-angle glaucoma. J Cataract Refract Surg. 2009;35(11):1946-1955.

8. Pereira FA, Cronemberger S. Ultrasound biomicroscopic study of anterior segment changes after phacoemulsification and foldable intraocular lens implantation. Ophthalmology. 2003;110(9):17991806.

9. Tham CC, Leung DY, Kwong YY, Li FC, Lai JS, Lam DS. Effects of phacoemulsification versus combined phaco-trabeculectomy on drainage angle status in primary angle closure glaucoma (PACG). J Glaucoma. 2010;19(2):119-123.

10. Altan C, Bayraktar S, Altan T, Eren H, Yilmaz OF. Anterior chamber depth, iridocorneal angle width, and intraocular pressure changes after uneventful phacoemulsification in eyes without glaucoma and with open iridocorneal angles. J Cataract Refract Surg. 2004;30(4):832-838.

11. Nolan WP, See JL, Aung T, et al. Changes in angle configuration after phacoemulsification measured by anterior segment optical coherence tomography. J Glaucoma. 2008;17(6):455-459.

12. Shin HC, Subrayan V, Tajunisah I. Changes in anterior chamber depth and intraocular pressure after phacoemulsification in eyes with occludable angles. J Cataract Refract Surg. 2010;36(8):1289-1295.

13. Huang G, Gonzalez E, Peng PH, Lee R, Leeungurasatien T, He M, et al. Anterior chamber depth, iridocorneal angle width, and intraocular pressure changes after phacoemulsification: narrow vs open iridocorneal angles. Arch Ophthalmol. 2011;129(10):1283-1290.

14. Huang G, Gonzalez E, Lee R, Chen YC, He M, Lin SC. Association of biometric factors with anterior chamber angle widening and intraocular pressure reduction after uneventful phacoemulsification for cataract. J Cataract Refract Surg. 2012;38(1):108-116.

15. Lee RY, Kasuga T, Cui QN, Huang G, Wang SY, Lin SC. Ethnic differences in intraocular pressure reduction and changes in anterior segment biometric parameters following cataract surgery by phacoemulsification. Clin Experiment Ophthalmol. 2013;41(5):442-449.

16. Issa SA, Pacheco J, Mahmood U, Nolan J, Beatty S. A novel index for predicting intraocular pressure reduction following cataract surgery. Br J Ophthalmol. 2005;89(5):543-546.

17. Kashiwagi K, Kashiwagi F, Tsukahara S. Effects of small-incision phacoemulsification and intraocular lens implantation on anterior chamber depth and intraocular pressure. J Glaucoma. 2006;15(2):103-9.

18. Radhakrishnan S, See J, Smith SD, et al. Reproducibility of anterior chamber angle measurements obtained with anterior segment optical coherence tomography. Invest Ophthalmol Vis Sci. 2007;48(8):3683-3688.

19. Chan JB, Yuen LH, Huang EH, et al. Reproducibility of cornea measurements in anterior segment OCT images of normal eyes and eyes with bullous keratopathy analyzed with the Zhongshan Assessment Program. Invest Ophthalmol Vis Sci. 2011;52(12):8884-8890.

20. Yang HS, Lee J, Choi S. Ocular biometric parameters associated with intraocular pressure reduction after cataract surgery in normal eyes. Am J Ophthalmol. 2013;156(1):89-94 e1.

21. Pradhan S, Leffler CT, Wilkes M, Mahmood MA. Preoperative iris configuration and intraocular pressure after cataract surgery. J Cataract Refract Surg. 2012;38(1):117-23.

22. Hayashi K, Hayashi H, Nakao F, Hayashi F. Effect of cataract surgery on intraocular pressure control in glaucoma patients. J Cataract Refract Surg. 2001;27(11):1779-86. 
23. Kucumen RB, Yenerel NM, Gorgun E, Kulacoglu DN, Oncel B, Kohen MC, et al. Corneal biomechanical properties and intraocular pressure changes after phacoemulsification and intraocular lens implantation. J Cataract Refract Surg. 2008;34(12):2096-8. 